\title{
Evaluation of retrograded starch as excipient for controlled release matrix tablets
}

\author{
Ana Cristina Diniz Recife ${ }^{a}$, Andréia Bagliotti Meneguin ${ }^{\mathrm{b}}$, \\ Beatriz Stringhetti Ferreira Cury ${ }^{a,}{ }^{*}$, Raul Cesar Evangelista ${ }^{\mathrm{a}, 1}$ \\ a Department of Drugs and Pharmaceuticals, School of Pharmaceutical Sciences, São Paulo State University-UNESP, 14800-903, Araraquara, SP, Brazil \\ ${ }^{\mathrm{b}}$ Interdisciplinary Laboratory of Advanced Materials, Centro de Ciências da Natureza - CNN, Universidade Federal do Piauí - UFPI, 64049-550, Teresina, PI, \\ Brazil
}

\section{A R T I C L E I N F O}

\section{Article history:}

Received 2 January 2017

Received in revised form 30 May 2017

Accepted 5 June 2017

Available online 7 June 2017

\section{Keywords:}

Retrograded starch

Pectin

Biodegradable polymers

Matrix tablets

Dissolution

\begin{abstract}
A B S T R A C T
High amylose starch (HAS) was retrograded by two different methods. The physicochemical properties of the retrograded materials were evaluated and structural changes were highlighted. Micromeritics properties were demonstrated as suitable for the compression process. Hydrophilic matrices were prepared by dry granulation of the retrograded starch. The in vitro release of diclofenac sodium (DS) in media with different $\mathrm{pH}$ values (1.2 and 7.4) was evaluated. The release profiles demonstrated the lowering of drug release rates in acid medium, mainly when pectin was associated to the matrix by physical mixture. In enteric medium, increased rates of drug release were observed, so that $t_{80 \%}$ occurred at approximately $60 \mathrm{~min}$, while for the tablets obtained with HAS, this time was of approximately $120 \mathrm{~min}$. The matrix obtained with pectin (during retrogradation and by physical mixture) enabled a more effective control over the drug release rates, so that $t_{80 \%}$ of DS was $150 \mathrm{~min}$ and $210 \mathrm{~min}$, respectively.
\end{abstract}

๑) 2017 Elsevier B.V. All rights reserved.

\section{Introduction}

Despite the wide and successful research with alternative routes of drug administration, the oral route remains the preferable choice because of its inherent benefits, such as safety, easy administration, flexibility of formulation, greater patient adherence to the treatment and the possibility of releasing drugs both locally and systemically [1,2]. Among oral controlled release systems, matrix tablets were noteworthy by presenting efficient manufacturing technology and high reproducibility, which reflects in lower costs of production, mainly when the direct compression of the powders is their way of obtainment $[3,4]$.

Swellable hydrophilic matrices are monolithic systems that do not degrade upon contact with the aqueous medium, undergoing hydration, which leads to the formation of a swollen diffusion layer, controlling the rates of release. The polymer swelling, the solute

\footnotetext{
* Corresponding author.

E-mail addresses: dinizrecife@yahoo.com.br (A.C.D. Recife), abagliottim@ hotmail.com (A.B. Meneguin), curybsf@fcfar.unesp.br (B.S.F. Cury), raulrasec@ yahoo.com.br (R.C. Evangelista).

1 in memorian.
}

diffusion throughout the matrix, and erosion are also mechanisms involved in the control of drug release $[5,6]$.

Natural polymers play an important role in the design of these systems, since they are materials from renewable and abundant sources, additionally, they are nontoxic and biodegradable. Besides, they can confer or enhance controlled release properties to the systems due to molecular properties of polymers, such as their monomer nature and type/degree of substitution [7-9]. Furthermore, in situ drug release can be reached because of the presence of glycoside bonds in the polymer structure that are hydrolytically cleaved by colonic enzymes [10].

Starch, a natural high molecular weight polysaccharide composed by glucose units, has received great attention as a carrier of matrix tablets, since it can be modified by a number of physical, chemical and enzymatic procedures, such as cross-linking [11], pregelatinization [12], retrogradation [13], complexation [14] and others, considering that native starch does not present suitable properties to reach desired drug release rates [12,13,15].

The retrogradation process of the starch, which occurs by hydrothermal treatments, converts the pregelatinized starch (amorphous) to a more resistant and compacted crystalline form [16,17], known as resistant starch $(R S)$, which can exist in different 
subtypes. RS-I is physically inaccessible to digestion by its entrapment in the matrix of grains, seeds and legumes, whereas RS-II corresponds to the non-gelatinized starch (native granular starch). RS-III is the retrograded starch and finally RS-IV is the chemically modified starch. However, advantages such as high thermal stability and low water solubility are attributed to the RSIII $[13,18]$.

$R S$ has been considered a promising material for the development of systems intended for colonic drug delivery, since such starch fraction is not absorbed in the stomach and the small intestine, but is selectively degraded by the microbiota of the colon [19-21]. In this regard, the colon has been viewed as an important site for drug delivery due to reduced proteolytic activity, longer transit time, and $\mathrm{pH}$ values close to neutrality, being effective not only in the treatment of local pathologies, such as ulcerative colitis, Crohn's diseases, colon carcinomas and infections [22], but also in the treatment of systemic pathologies. Besides, the colon represents an important site for oral administration of proteins [23,24]. The brush-border present in the colonic membrane and the high responsiveness of the mucosa make the colon a site with increased chances of drug absorption [25].

Recently, a great number of studies have shown that high amylose starch (HAS) - a hybrid variety of starch composed of amylose and amylopectin (70:30) [26] - is the more suitable material to obtain high levels of $R S$ because the crystallites formed remain embedded in the amylose matrix and thereby they are protected from rapid exposure to digestive enzymes [16,27].

Pectin $(P)$ is a natural polysaccharide composed mainly by homogalacturonans and rhamnogalacturonans residues, which correspond to linear and smooth fractions, respectively [28]. It has been used as excipient for targeting drugs to the colon, because when in contact with acid medium, it remains as macromolecular aggregates and due to its digestibility by colonic microbiota [29]. In our research group, the impact of the pectin addition onto release properties has been studied in different drug delivery systems, such as cross-linked HAS/P matrices loaded with nimesulide [30], mucoadhesive beads of gellan gum $/ P$ intended to the controlled release of ketoprofen [31], blends of cross-linked HAS/P loaded with DS [11], free films of HAS/P mixtures cross-linked with sodium trimetaphosphate [32], colon-specific films coating based on $R S / P$ [13], and more recently, $R S / P$ free-standing films reinforced with nanocellulose to colon-specific release of methotrexate [33].

Based on promising results, the use of the $R S$ and $R S / P$ blend as an excipient to design hydrophilic matrix tablets was evaluated. Henceforth, HAS was retrograded by two different methods (through constant temperature and thermal cycles), in order to verify its impact on the $R S$ yield and on the performance of tablets as a controlled release system. DS, a nonsteroidal antiinflammatory drug (NSAID), was used as a model drug. The physicochemical (crystallinity, swelling and porosity) and thermal (TG/ $D T G$ ) properties of such retrograded materials were evaluated, as well as micromeritic properties (size distribution, density and flow). The performance of the materials as tablet excipient intended to the control of drug release rates throughout gastrointestinal tract (GIT) was evaluated by in vitro tests in media with different $\mathrm{pH}$ values (1.2 and 7.4).

\section{Materials and methods}

\subsection{Materials}

High amylose corn starch (Hylon VII type - 70\% amylose, lot:HA9140) was obtained from National Starch \& Chemical (New Jersey, USA), sodium hydroxide (lot: 611648) was supplied by Grupo Química (Rio de Janeiro, Brazil), 37\% hydrochloric acid (lot:
29957) was provided by Quimis (Diadema, Brazil), diclofenac sodium was purchased from Henrifarma (São Paulo, Brazil), pectin (type LM-5206CS - DE < 50\%, lot: S74431) was provided by CP Kelco (Copenhagen, Denmark), pancreatin (lot: 0903372) was purchased from Vetec (Duque de Caxias, Brazil), 3,5-dinitrosalicylic acid (purity $\geq 98.0 \%$, lot: $125 \mathrm{k} 3664$ ) was provided by Sigma-Aldrich Co. (St. Louis, USA), purified water (Milli Q, Millipore).

\subsection{Methods}

\subsubsection{Retrogradation of high amylose starch (HAS)}

Aqueous dispersions of $H A S$ at different concentrations (20 or $40 \%$ ) were autoclaved at $121{ }^{\circ} \mathrm{C}(15 \mathrm{~min})$ for starch gelatinization. The gelatinized starch (GS) was retrograded according to two different methods in order to assess the impact of the storage time and temperature in the material properties. In $M 1$, the temperature was kept constant $\left(4^{\circ} \mathrm{C}\right)$ for 8 days (isothermal cycle) and in $\mathrm{M} 2$ it was employed alternating cycles of temperature $\left(4^{\circ} \mathrm{C}\right.$ and $30^{\circ} \mathrm{C}, 2$ days at each temperature) for 16 days [34]. All samples were dried in a forced air circulation oven-drier at room temperature until constant weight.

Retrograded samples were labeled as M120, M140, M220 and $M 240$ respective to the method of retrogradation (M1 or M2) and concentration of polymers (20 or $40 \%$ ). In this sense, the M220 sample was those obtained from M2 method and composed by $20 \%$ of polymer.

\subsubsection{Enzymatic digestion and resistant starch content}

In order to eliminate $R S I$ and $R S I I$ fractions, a known mass (100 mg) of HAS, M120, M140, M220 and M240 samples were mixed with $2 \mathrm{~mL}$ of phosphate buffer $(0.1 \mathrm{~mol} / \mathrm{L} ; \mathrm{pH} 7.1)$ and kept in water bath $\left(100{ }^{\circ} \mathrm{C}\right)$ by $30 \mathrm{~min}$ [35]. After that, cooled samples were incubated in $0.5 \mathrm{~mL}$ of a pancreatin enzymatic solution $(0.15 \mathrm{~g} / \mathrm{mL})$, at $37^{\circ} \mathrm{C}$ for different times $(20,60,120,150$ and $180 \mathrm{~min})$. Ethanol (80\%) was added to the samples for stopping the enzymatic activity.

The glucose content provided by starch hydrolysis was quantified by the reaction with 3.5-dinitrosalicylic acid (DNS) [36] based on the standard glucose. Both RDS (rapid digestible starch digested at $20 \mathrm{~min}$ ) and SDS (slowly digestible starch - digested between 20 and $120 \mathrm{~min}$ ) were used to calculate $R S$ content, according to Equation (1) [37]:

$R S=\frac{(\text { Total Starch }- \text { RDS }-S D S)}{\text { Total Starch }} \times 100$

\subsubsection{Physicochemical characterization of samples}

2.2.3.1. Moisture content. Moisture content of HAS, M120, M140, M220 and M240 samples was assessed gravimetrically on analytical infrared moisture balance (MettlerTM, PL 200/LP 11). A sufficient mass of samples (about $1 \mathrm{~g}$ ) was uniformly disposed on the metallic pan of the balance and heated by infrared $\left(105^{\circ} \mathrm{C}\right)$ until constant weight was reached. The results were expressed as percentage of water loss in relation to the initial mass [38].

2.2.3.2. X-ray diffraction (XRD) analysis. Crystallinity patterns of the GS, HAS, M120, M140, M220 and M240 samples were evaluated from their diffractograms recorded on a X-ray diffractometer (Siemens $^{\circledR}$ - Model D5000; Germany), using nickel-filtered $\mathrm{Cu} \mathrm{K \alpha}$ radiation ( $\lambda=1.5406 \AA$ ) (tube operating at $40 \mathrm{kV}$ and $30 \mathrm{~mA}$ ). The scanning regions were collected from 4 to $70^{\circ}(2 \theta)$ in step size of $0.05^{\circ}(2 \theta)$. 
2.2.3.3. Thermogravimetric (TG) and derivative thermogravimetric (DTG) analysis. TG/DTG analysis of the GS, HAS, M120, M140, M220 and M240 samples were performed via a TA Instruments (SDT 600) (New Castle, DE, USA) at a heating rate of $10^{\circ} \mathrm{C} / \mathrm{min}$, from 25 to $600{ }^{\circ} \mathrm{C}$, under nitrogen atmosphere (flow rate of $50 \mathrm{~mL} / \mathrm{min}$ ), in open cylindrical alumina pans containing about $5 \mathrm{mg}$ of sample.

\subsubsection{Micromeritic properties}

2.2.4.1. Granulometric distribution. The particle size distribution analysis was performed using a set of test sieves $(0.297 ; 0.250$; $0.210 ; 0.177 ; 0.125 \mathrm{~mm}$ ) attached to a sieve shaker (Haver \& Bocker Model EML Digital Plus, Westfalen, Germany) operated by $20 \mathrm{~min}$. The average particle diameter was calculated according Equation (2) [39]:

$\mathrm{d}_{a v g}=\sum \frac{(M O \cdot F r \%)}{100}$

where $d_{a v g}$ is the arithmetic average diameter ( $\left.\mathrm{mm}\right)$; $M O$ is the average of passage and retention mesh opening ( $\mathrm{mm}$ ) and $\mathrm{Fr} \%$ is the percentage of mass retained on each sieve.

2.2.4.2. Apparent bulk and tapped densities. The apparent bulk $\left(d_{b}\right)$ and tapped $\left(d_{t}\right)$ densities were indirectly determined from the apparent and tapped volume measurements, respectively. A known mass (about $10 \mathrm{~g}$ ) of $H A S, M 120, M 140, M 220, M 240$ samples and the $D S+M 120, D S+M 140, D S+M 220$ and $D S+M 240$ physical mixtures $(P M)$ were introduced in a $25 \mathrm{~mL}$ graduated cylinder glass and the bulk volume $\left(V_{b}\right)$ was recorded. After this, to determine the tapped volume $\left(V_{t}\right)$, the samples were submitted to cycles of 1250 taps in an automatic volumeter compactor (Volumeter Tapped, model SVM, ERWEKA, Heusenstamm, Germany) until the difference between two consecutive measurements was lesser than $2 \%$. The values of $d_{b}$ and $d_{t}$ were calculated according to Equations (3) and (4):

$d_{b}=\frac{m}{V_{b}}$

$d_{t}=\frac{m}{V_{t}}$

where $d_{b}=$ bulk apparent density $(\mathrm{g} / \mathrm{mL}) ; d_{t}=$ tapped apparent density; $m=$ mass $(\mathrm{g}) ; V_{b}=$ apparent bulk volume $(\mathrm{mL})$ and $V_{t}=$ apparent tapped volume $(\mathrm{mL})$.

2.2.4.3. Analysis of flow ability. The angle of repose was determined according to free base cone technique [40]. An accurately mass $(20 \mathrm{~g})$ of HAS, M120,M140,M220, M240 samples and the DS + M120, $D S+M 140, D S+M 220$ and $D S+M 240$ physical mixtures $(P M)$ was introduced in a stainless steel funnel (14 mm opening) coupled to a vibrating device. The orifice of the funnel was opened and the powder flowed onto a flat surface. The $\alpha$ angle was calculated by Equation (5):

$\tan \alpha=\frac{h}{r}$

where $h=$ cone height $(\mathrm{cm})$ and $r=$ base radius of cone $(\mathrm{cm})$.

\subsubsection{Porosity determination}

The porosity of the GS, HAS, M120, M140, M220 and M240 samples was evaluated on ASAP 2010 surface area analyzer (Micrometrics ${ }^{\circledR}$ ), according to gas adsorption-desorption technique using $\mathrm{N}_{2}(\mathrm{~T}=77.35 \mathrm{~K})$ as the adsorptive gas. Specific surface area, pore volume and pore size were calculated from isotherms of nitrogen adsorption/desorption by the Brunauer-Emett-Teller (BET) method [41] over a relative pressure range of $0.05-0.25$ on the adsorption branch.

\subsubsection{Liquid uptake ability}

The determination of liquid uptake ability of samples was carried out on an Enslin's device $[13,32,42,43]$. About $0.05 \mathrm{~g}$ of samples were accurately weighed and carefully disposed on the sintered glass filter of funnel. The volume of different media $(0.1 \mathrm{~N} \mathrm{HCl}, \mathrm{pH}$ $1.2 ; 0.1 \mathrm{~mol} / \mathrm{L}$ phosphate buffer $\mathrm{pH} 7.4$ and 6.8 ) absorbed by the samples was measured on the graduated pipette of the device at different times for $120 \mathrm{~min}$ and expressed as medium absorbed (\%) in relation to initial mass of sample. The tests were performed in triplicate. Samples containing DS were also evaluated.

\subsubsection{Preparation of tablets}

Tablets were produced by dry granulation of excipients, in which retrograded samples and control samples were compressed (single punch machine KORSHI AR 400 -Erweka ${ }^{\mathbb{B}} ; 10 \mathrm{~mm}$ punch and die set), milled in a mortar and calibrated on a sieve $(0.297 \mathrm{~mm}$ mesh opening). The granulated excipients $(300 \mathrm{mg}$ ) were thoroughly mixed with $D S(100 \mathrm{mg}$ ) and compressed to producing tablets with a minimal hardness of $30 \mathrm{~N}$. Tablets were labeled according to 2.2.1 section, however $M$ prefix was replaced by the $T$ prefix, resulting in T120, T140, T220 and T240 samples.

For comparative analysis, tablets of retrograded starch/pectin (added RSP suffix) and retrograded starch and pectin physical mixture (added RSP-M suffix) were also evaluated. Retrograded starch/pectin materials were prepared according to procedure previously described by Meneguin et al. (2014).

\subsubsection{Physical properties of tablets}

Forty tablets were weighed on an analytical balance Owa Labor ${ }^{\circledR}$ and the mean and standard deviation was calculated [44]. Tablets hardness was determined using a durometer Schleuniger Pharmatron ${ }^{\circledR}-6 \mathrm{D}$ model $(\mathrm{n}=30)$. Thickness of 30 tablets was measured using an electronic micrometer (Mitutoyo MDC-M293, Tokyo, Japan) immediately after the compression and after $24 \mathrm{~h}$. Friability was determined on Erwek ${ }^{\circledR}$ friabilator (TA 20 model) with 20 tablets accurately weighed and submitted to 100 revolutions. After rotations, tablets were carefully cleaned and weighed again. The mass loss during the test was calculated according Equation (6):

$\operatorname{Friability}(\%)=\frac{W_{i}-W_{f}}{W_{f}} \times 100$

Where $W_{i}=$ initial tablet weight $(\mathrm{g})$ and $W_{f}=$ final tablet weight (g).

\subsubsection{In vitro dissolution study}

Dissolution tests of tablets were carried out using USP type II dissolution apparatus (paddle) in a Hanson Research (New Hanson SR-8 Plus) dissolution station, according to sink conditions. The system was kept at $37 \pm 0.5{ }^{\circ} \mathrm{C}$ under $50 \mathrm{rpm}$ rotation speed. Buffer solutions with different $\mathrm{pH}$ values were used $(900 \mathrm{~mL}$ per vessel). At first, test was performed at $\mathrm{HCl}$ solution $(0.1 \mathrm{~N}, \mathrm{pH} 1.2)$ containing $1.5 \%$ of polysorbate 80 for $120 \mathrm{~min}$, followed by step at phosphate buffer $(0.1 \mathrm{~mol} / \mathrm{L}, \mathrm{pH} 7.4)$ for $240 \mathrm{~min}$. Aliquots $(5 \mathrm{~mL})$ were collected at different times with replacement of equal volume medium. The amount of DS released from tablets $(100 \mathrm{mg})$ was determined on a UV-VIS spectrophotometer $(\lambda=296 \mathrm{~nm}$ for acid medium and $\lambda=276 \mathrm{~nm}$ for phosphate buffer). The $t_{80 \%}$ (time required to release $80 \%$ of drug) was determined. Analysis were performed in triplicate. 
2.2.9.1. Analysis of in vitro drug release mechanism. The analysis of mechanisms of drug release process was performed and dissolution data obtained in 2.2.9 section were fitted (SigmaPlot 10.0 software) to mathematical models like Korsmeyer-Peppas and Weibull. Mathematical models were fitted only until 60 and $63.2 \%$ of data, respectively.

\subsubsection{Statistical analysis}

When applied, the results were treated by one-way analysis of variance (ANOVA) to assess the significance of the differences between data. Tukey-Kramer post-test was used to compare the means of different treatment data (GraphPad Prism 5 software). Results with $\mathrm{p}<0.05$ were considered statistically significant.

\section{Results and discussion}

\subsection{Enzymatic digestion and resistant starch content}

The hampered digestibility of $R S$ is due to the packing of amylose double helices, which reduces the access of $\alpha$-amylase to glycosidic linkages $[13,45]$. The specific enzymatic digestion of $R S$ in the colon assigns the retrograded samples as a promising material to the development of carriers that aim to target the drug to the colon $[46,47]$.

The results of the resistance against enzymatic digestion of HAS, GS (40\% HAS dispersion), M120, M140, M220 and M240 samples are presented in Table 1. It was found that the original RS content present in the HAS was $57.07 \%$, however, the gelatinization process promoted its significant reduction, getting to levels of about $44 \%$, since this process destroys the molecular order of the starch granule, making it more easily digested [48].

The amount of RS in M220 and M240 samples was improved (75.84-76.55\%) and greater, in relation to those presented in $M 120$ and M140 samples (72.30-73.85\%). This raise in the $R S$ content can be attributed to increased temperature $\left(30^{\circ} \mathrm{C}\right)$ and storage time (16 days) employed in $M 2$, which allowed a higher mobility of polymeric chains, promoting a more extensive structural rearrangement followed by the increasing of crystallinity.

Furthermore, temperatures near to $\operatorname{Tg}$ (around $6{ }^{\circ} \mathrm{C}$ ), favor the nucleation of crystals, while higher temperatures $\left(30-40{ }^{\circ} \mathrm{C}\right.$ ) contribute for their propagation. So, when retrogradation is performed by using alternating thermal cycles, the crystallization rate is increased, and more perfect crystallites are built [34,49]. Park [34] also reported an increase of $R S$ yield from waxy maize starch by retrogradation alternating thermal cycle against the isothermal cycle.

The different polymeric concentrations (20 and 40\%) employed may also have influenced on starch retrogradation, since samples prepared with $40 \%$ of HAS led to the highest amounts of $R S$ (73.85\%-76.55\%), in contrast with samples at lowest concentration that yielded about $72.30 \%-75.84 \%$ of $R S$. There is a great number of chains to interact with each other when the amylose is in highest concentrations, promoting the great crystallization of the structure [50].

\subsection{Physicochemical characterization}

\subsubsection{Moisture content}

The moisture content can affect a set of physical and mechanical properties, and therefore contributing to decrease the apparent density of particles, affecting the compressibility, porosity, flow ability and the dissolution of tablets [51]. Furthermore, the moisture existent in the drug accelerates its hydrolysis as well as facilitates the reactions to excipients and adjuvants [52].

According to Table 1, the moisture content of samples is within the limits for starch (from 10 to 14\%) [53]. The slightly lower water content of M2 samples can be attributed to the alternated temperatures for starch retrogradation $\left(4^{\circ} \mathrm{C}\right.$ and $\left.30^{\circ} \mathrm{C}\right)$, and higher time of retrogradation (16 days), which favor the evaporation of water. Moreover, the lower moisture of some materials is frequently associated to a higher structural crystallinity, since less hydroxyl groups will be available for interacting with water molecules [54]. This relation can be confirmed by XRD patterns (3.2.2 section), in which the samples that had lower water content (M2 samples), also showed different crystallinity patterns indicated by the presence of an additional peak at $13^{\circ}(2 \theta)$.

\subsection{2. $X$-ray diffraction measurements (XRD)}

$H A S$ is a semi crystalline polymer and it presents different crystalline structures. The X-ray diffractogram of the HAS sample (HYLON VII) (Fig. 1 ) exhibited pronounced peaks at $17.02^{\circ}$ and $23^{\circ}$ $(2 \theta)$, which are characteristic of the $B$ polymorph. The peak at $25^{\circ}$

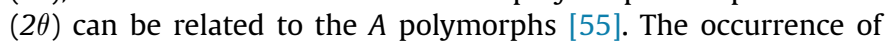
peak at $19.8^{\circ}(2 \theta)$ indicates the occurrence of the $V$ polymorph, suggesting a highly ordered crystalline structure of amylose-lipid complexes into starch granules $[11,46,56]$. XRD of HAS demonstrated that it consists of a heterogenic mix of $B$ and $V$ structures as previously reported by Shamai [57].

The GS diffractogram evidenced the disappearance of the main characteristic peaks of the HAS, showing a predominantly amorphous pattern as the gelatinization process promotes the disruption of starch granules, leading to disappearing of crystalline regions $[58,59]$.

In the $M 120$ and $M 140$ diffractograms, peaks about $17^{\circ}, 19.8^{\circ}$ and $23^{\circ}(2 \theta)$ were maintained, which are related to the predominance of the $B$ type $\left(\sim 17^{\circ}\right.$ and $\left.23^{\circ}(2 \theta)\right)$ and the $V$ type $\left(19.8^{\circ}(2 \theta)\right)$ polymorphs while the peak at $25^{\circ}(2 \theta)$ disappeared. In the XRD patterns of M220 and M240 the same peaks observed for M120 and M140 were preserved, but the peak around $13^{\circ}(2 \theta)$ was more intense, which is related to the $V$ crystalline structure [57] and such change is indicative of the resistant starch presence. Cui [27] reported that the $V$ type crystallinity reduces the water uptake of starch granules and make them more resistant to digestive enzymes.

Table 1

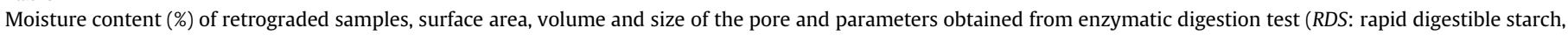
$L D S$ : low digestible starch, RS: retrograded starch).

\begin{tabular}{|c|c|c|c|c|c|c|c|}
\hline Samples & $R D S(\%)$ & $\operatorname{LDS}(\%)$ & $R S(\%)$ & Moisture content (\%) & Surface area $(B E T)\left(\mathrm{m}^{2} / \mathrm{g}\right)$ & Pore volume $\left(\mathrm{cm}^{3} / \mathrm{g}\right)$ & Pore size $(\AA)$ \\
\hline HAS & $18.48 \pm 0.012$ & $24.45 \pm 0.025$ & $57.07 \pm 0.023$ & $12.23 \pm 0.321$ & - & - & - \\
\hline GS & $17.13 \pm 0.014$ & $38.07 \pm 0.014$ & $44.80 \pm 0.003$ & - & No measurable & No measurable & No measurable \\
\hline M120 & $10.58 \pm 0.003$ & $17.12 \pm 0.018$ & $72.30 \pm 0.015$ & $7.30 \pm 0.100$ & 0.023 & 0.000246 & 28.185 \\
\hline M140 & $11.02 \pm 0.003$ & $15.12 \pm 0.029$ & $73.85 \pm 0.026$ & $7.06 \pm 0.152$ & 0.206 & 0.000567 & 28.218 \\
\hline M220 & $10.40 \pm 0.002$ & $13.77 \pm 0.013$ & $75.84 \pm 0.015$ & $7.13 \pm 0.057$ & 0.030 & 0.003504 & 28.345 \\
\hline M240 & $10.56 \pm 0.015$ & $12.90 \pm 0.007$ & $76.55 \pm 0.022$ & $7.00 \pm 0.100$ & 1.098 & 0.000764 & 28.306 \\
\hline
\end{tabular}




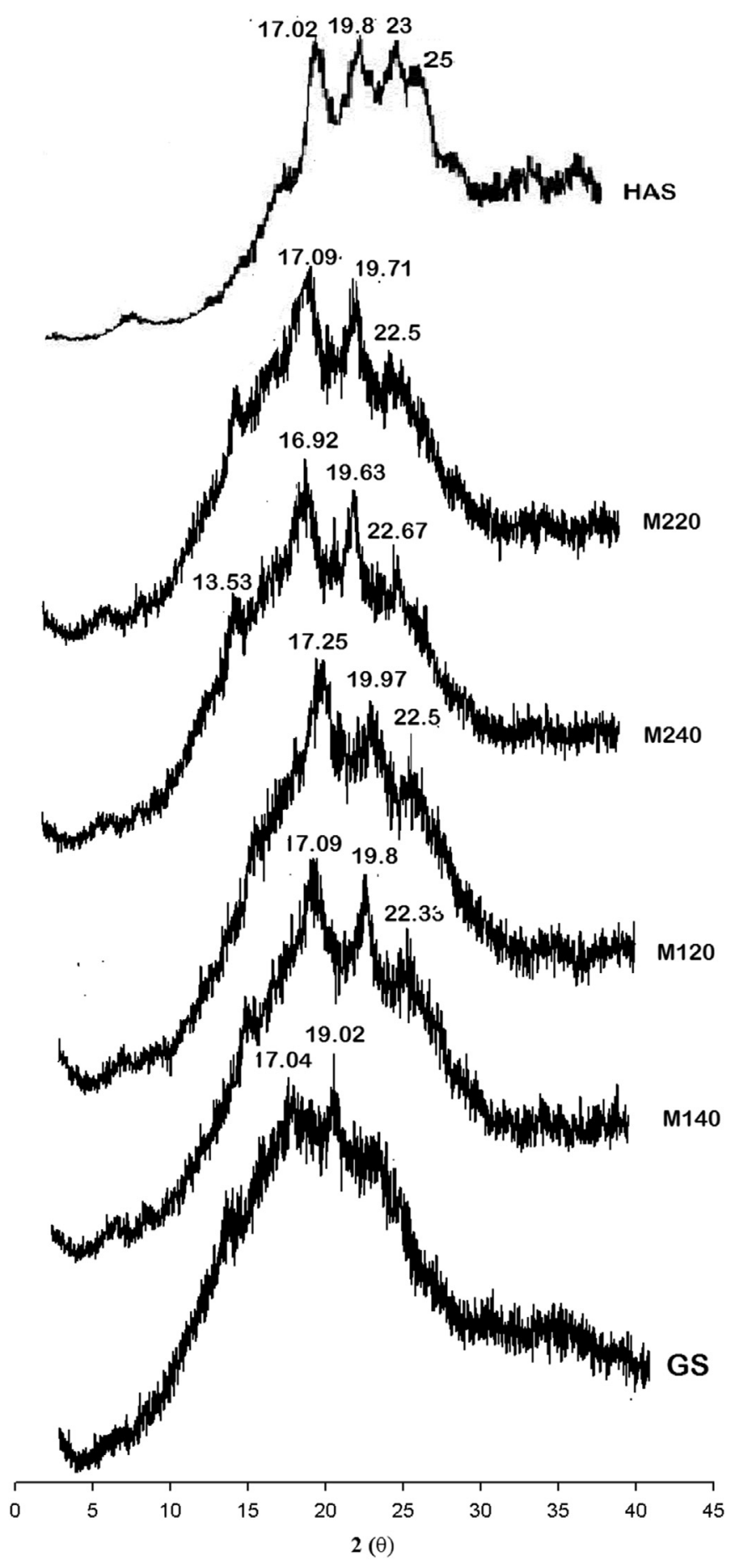

Fig. 1. X-ray diffraction patterns of the samples.

\subsubsection{Thermogravimetric (TG) and derivative thermogravimetric (DTG) analysis}

The TG/DTG curves of M120, M140, M220 and M240 samples displayed in Fig. 2 show a first degradation stage between 40 and $110{ }^{\circ} \mathrm{C}$, which is related to the moisture evaporation during the heating, according to previous studies with other polysaccharides [33]. The second and main stage of degradation (69-75\%) occurred between 250 and $350{ }^{\circ} \mathrm{C}$ and it was related to the elimination of polyhydroxyl groups, followed by the depolymerization and decomposition of the starch [60].
The GS showed $66 \%$ of mass loss and the principal degradation event occurred between $200{ }^{\circ} \mathrm{C}$ and $300{ }^{\circ} \mathrm{C}$, while the degradation peak of the samples submitted to retrogradation process shifted to highest values, indicating that the process promoted the increase of thermal stability. Besides, this set of results evidences the lower thermal stability of the GS attributed to the granular structure loss due to the heating in water excess [61].

The preparation method and amylose concentration did not influence the thermal behavior, since no significant differences between the TG/DTG curves of M1 and M2 samples were observed.

\subsection{Micromeritic properties}

\subsubsection{Granulometric distribution}

It was possible to observe a great similarity among granulometric distribution profiles of M120, M140, M220 and M240 samples (Fig. 3), and the higher size frequency for all samples ranging between $0.210 \mathrm{~mm}$ and $0.250 \mathrm{~mm}$ (about 26.15\%). There was no difference between the values of the mean diameter (about $0.19 \mathrm{~mm}$ ) $(\mathrm{p}>0.05)$.

\subsubsection{Bulk and tapped apparent densities}

Bulk density and tapped density of M120, M140, M220 and M240 samples and their physical mixtures (PM) with DS (Table 2) were statistically different $(\mathrm{p}<0.05)$. Retrograded samples containing $20 \%$ of polymer showed lower density values than those prepared with $40 \%$ of polymer, indicating that the increase of the starch concentration promoted the building of denser particles, which should lead to better flow properties [62]. Furthermore, PM exhibited higher values of both bulk and tapped densities. This density raise can be related to the presence of the drug, which probably led to a higher number of interparticle contacts, making powder more packed and dense [30].

\subsubsection{Analysis of flow ability}

The values of repose angle of samples (Table 2) were similar ( $p>0.05$ ) and ranged between $20^{\circ}$ and $30^{\circ}$, indicating their free flowing ability. On the other hand, the high value of repose angle of HAS $\left(39.96^{\circ}\right.$ ) demonstrated its poor flow. This behavior can be related to the lower moisture percentage of M120, M140, M220 and M240 (7-7.3\%) in relation to HAS (12.23\%) (Table 1). According to Albero [63], the decrease of flowability can be caused by the increase of the adhesion in existent points of contact between granules as a result of the water surface tension.

\subsection{Porosity determination}

Porosity represents the total sum of void spaces in solid materials in the form of pores, cracks and cavities of different sizes and shapes and it can influence important physical-chemical properties, such as adsorptive properties, mechanical strength, dissolution and wettability [64].

According to Table 1, porosity values for GS were not measurable. This fact can be associated to the starch heating in an aqueous medium that allows structural changes by the disruption of hydrogen bonds, which stabilize the granule internal crystal structure. Thus, an amorphous mass is formed, and therefore, it is not possible to observe the occurrence of pores, possibly because they are located in inaccessible regions for the adsorptive gas [65].

According to the results, it was observed that the surface area, the volume and size of these pores were affected mainly through the retrograded starch obtaining method, since samples prepared according M2 were more porous than those prepared by M1 (Table 1). This behavior can be related to the fact that the method that employed alternating cycles of temperature (M2) was 

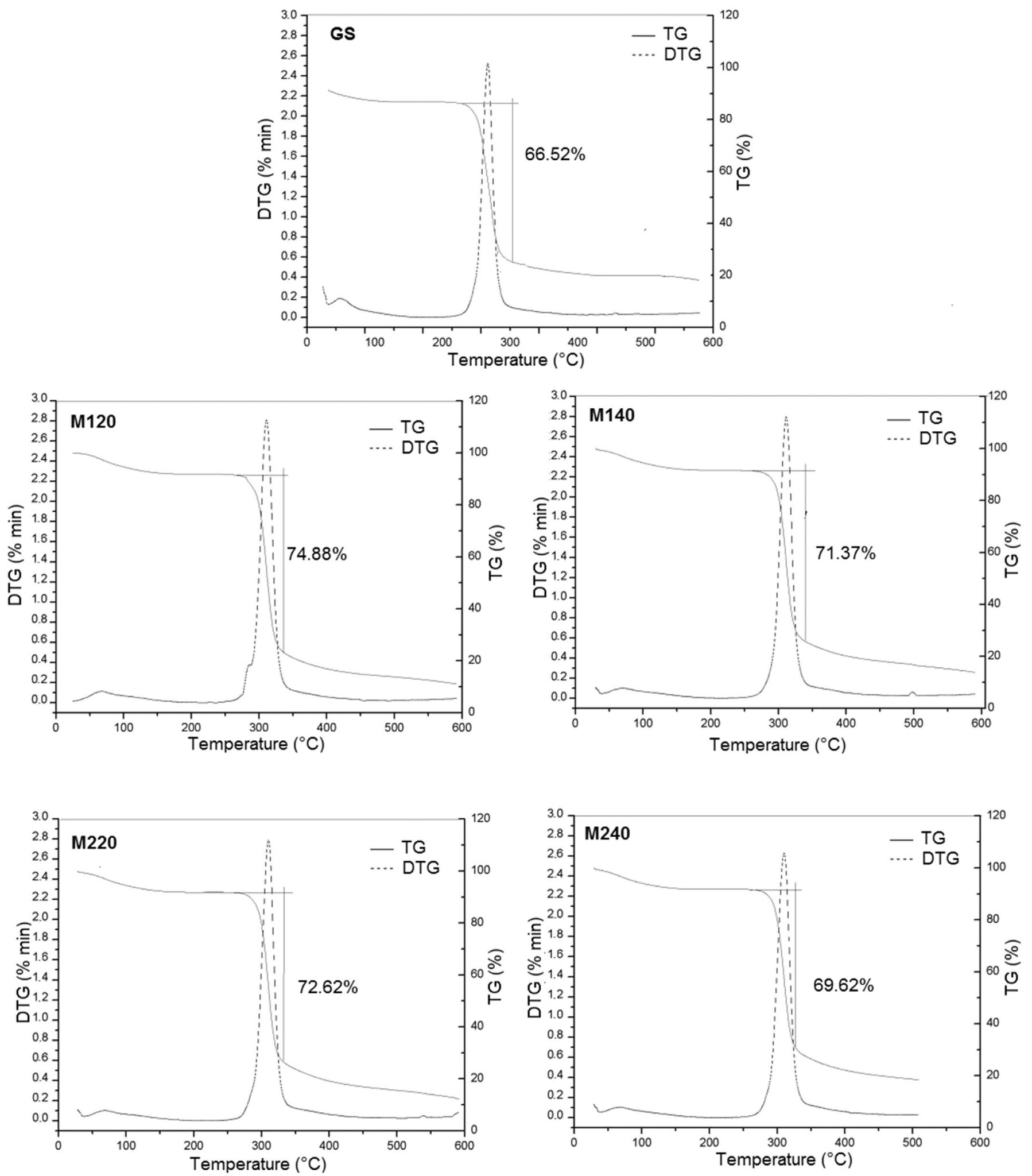

Fig. 2. TG/DTG curves of GS, M120, M140, M220 and M240 samples.

responsible for the construction of more crystalline structures, as already evidenced in the X-rays diffraction analysis (3.2.2 section).

Samples obtained with higher concentration of polymers (40\%) also showed higher values of surface area in relation to the others (20\%). In addition, such data are in agreement with the density data
(Table 2), in which 20\% samples exhibited lower density than $40 \%$ samples.

Based on the IUPAC pore size classification, in which microporous materials have pore diameters of less than $2 \mathrm{~nm}(20 \AA)$, mesoporous materials between $2 \mathrm{~nm}$ and $50 \mathrm{~nm}$ (20 Å e $500 \AA$ ) and 

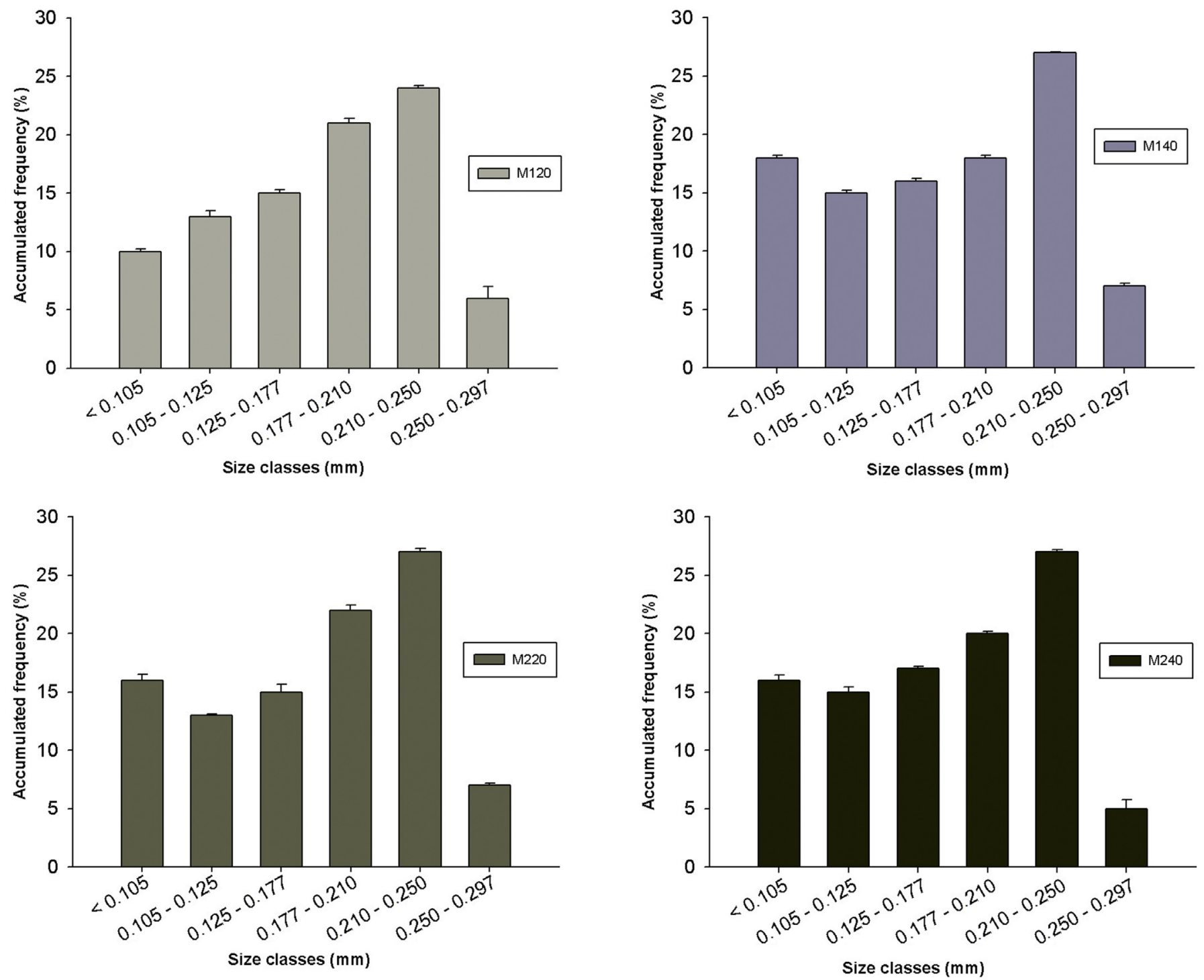

Fig. 3. Profile of granulometric distribution of the samples.

Table 2

Values of bulk and tapped density and angle of repose.

\begin{tabular}{|c|c|c|c|}
\hline Samples & Apparent bulk density $\left(d_{b}\right)(\mathrm{g} / \mathrm{mL})$ & Apparent tapped density $\left(d_{c}\right)(\mathrm{g} / \mathrm{mL})$ & Angle of repose $\left({ }^{\circ}\right)$ \\
\hline M120 & $0.721 \pm 0.011$ & $0.768 \pm 0.005$ & $30.92 \pm 0.60$ \\
\hline M140 & $0.733 \pm 0.006$ & $0.793 \pm 0.011$ & $30.58 \pm 0.60$ \\
\hline M220 & $0.725 \pm 0.022$ & $0.775 \pm 0.013$ & $30.35 \pm 0.67$ \\
\hline M240 & $0.738 \pm 0.002$ & $0.795 \pm 0.002$ & $30.69 \pm 0.41$ \\
\hline $\mathrm{PM}(\mathrm{DS}+\mathrm{M} 120)$ & $0.769 \pm 0.006$ & $0.813 \pm 0.007$ & $29.99 \pm 0.42$ \\
\hline PM (DS + M140) & $0.788 \pm 0.012$ & $0.865 \pm 0.019$ & $29.03 \pm 0.64$ \\
\hline $\mathrm{PM}(\mathrm{DS}+\mathrm{M} 220)$ & $0.776 \pm 0.008$ & $0.829 \pm 0.013$ & $29.74 \pm 0.65$ \\
\hline $\mathrm{PM}(\mathrm{DS}+\mathrm{M} 240)$ & $0.785 \pm 0.014$ & $0.864 \pm 0.012$ & $29.38 \pm 0.67$ \\
\hline HAS & $0.504 \pm 0.003$ & $0.590 \pm 0.014$ & $39.96 \pm 0.04$ \\
\hline
\end{tabular}

macroporous materials have a pore diameters greater than $50 \mathrm{~nm}$ (500 ̊) [66], all samples of this study have predominantly mesoporous structures.

\subsection{Liquid uptake ability}

The drug release rate from swellable matrices is controlled by three sequential events: water absorption, matrix swelling and drug diffusion throughout gel layer, and it can be influenced by ionic strength and/or dissolution medium $\mathrm{pH}[67,68]$.

All samples had a pH-responsive behavior (Fig. 4) with lower liquid uptake in acid medium ( $\mathrm{pH} 1.2$ ) than at $\mathrm{pH} 7.4$, which is an inherent behavior of anionic polymers. In acid medium, the hydrophilicity is lower because the carboxyl groups remain in their protonated form, causing a strong entanglement of the polymeric chains, and thus reducing the water entrance and retention [69]. 


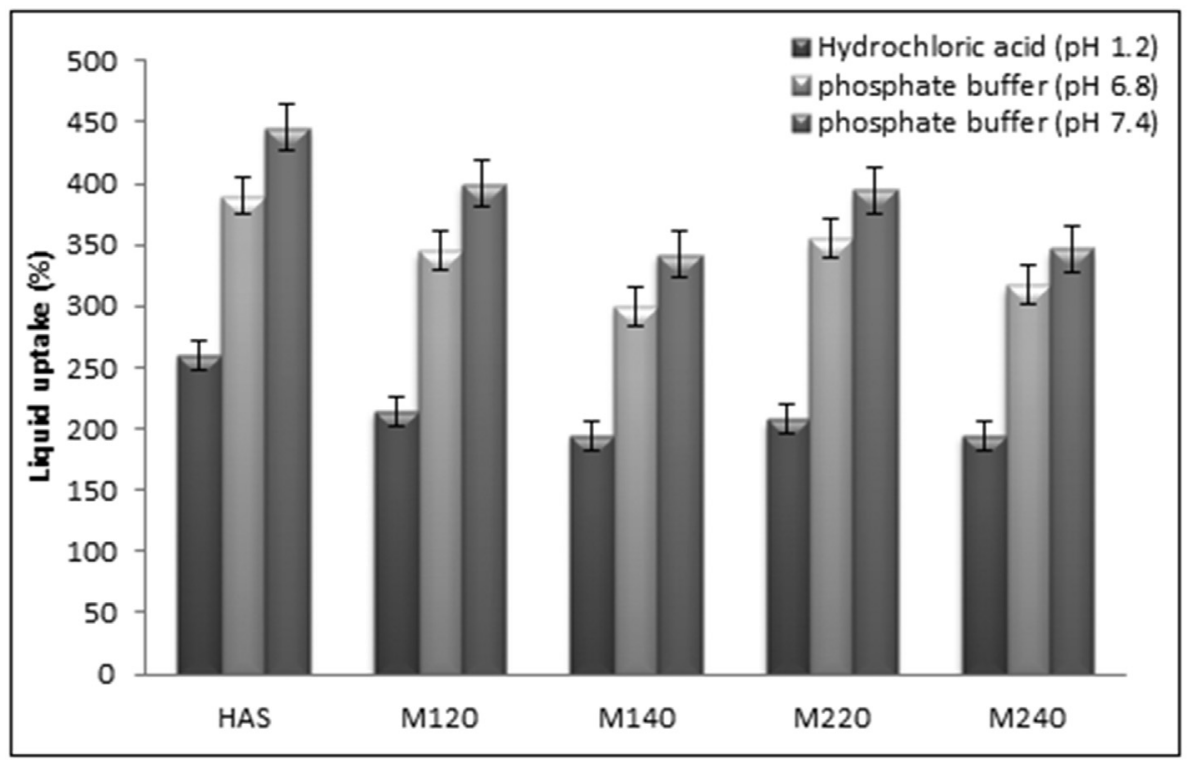

Fig. 4. Liquid uptake (\%) of samples at equilibrium (120 min) in different media.

Otherwise, the increase of $\mathrm{pH}$ values promotes the ionization of carboxyl groups and the consequent repulsion of chains with network dilation, which favors the water entrance [70].

M120, M140, M220 and M240 samples had a low water uptake compared to HAS due to changes in the crystallinity as a result of the starch retrogradation by the action of mechanical and thermal energy [71,72]. In fact, the presence of another polymorph, indicated by the appearance of a new peak in the DRX studies (3.2.2 section), may have resulted in different chain arrangements, with lower probability of hydroxyl groups interacting with water molecules [54], lowering the water uptake.

\subsection{Physical properties of tablets}

The physical parameters values of the tablets' quality (Table 3 ) showed low weight variation $(0.5-0.75 \%)$ on them, demonstrating that suitable flow properties of granules allowed the uniform filling of the die and punch set.

All tablets showed hardness greater than $30 \mathrm{~N}$ and friability lower than $1.0 \%$, indicating that the tablets have suitable mechanical strength and are resistant to breakage during packing, shipping and handling of the product [44].

After $24 \mathrm{~h}$ of obtaining the tablets, there was no significant increase in thickness (Table 3$)(p>0.05)$, indicating that the material did not undergo significant elastic recovery after compression.

\subsection{In vitro drug release profile}

There are several factors that can influence the kinetics of the drug release. Among them are drug properties as polymorphic form, crystallinity, particle size, solubility and the amount of drug incorporated into the dosage form. Physical properties of polymers, such as composition, molecular weight, crosslinking density and porosity also are decisive in the control of release rates [73].

When the hydrophilic matrix is in contact with GIT fluids, the surface hydration leads to a liquid uptake and to the formation of a swollen layer, which represents a physical barrier against the drug diffusion and controls the drug release rates [74].

DS, a nonsteroidal benzeneacetic acid derivative, belonging to BSC class II drug, has weak acidic properties ( $\mathrm{pKa} \sim 4$ ) and $\mathrm{pH}-$ dependent solubility, being practically insoluble in hydrochloric acid pH 1.2 (BARTOLOMEI et al., 2006; MERCK INDEX, 2006). DS release profiles from tablets with a different composition are presented in Fig. 5, which demonstrates that drug release rates in acid medium $(0.1 \mathrm{~N} \mathrm{HCl} ; \mathrm{pH} 1.2)$ were always lower than those shown in phosphate buffer ( $\mathrm{pH}$ 7.4). This $\mathrm{pH}$-dependent behavior is in agreement with the liquid uptake data, which increased with the change of medium $\mathrm{pH}$ of $1.2-7.4$. Besides, at acid $\mathrm{pH}$, DS is in the protonated form, and therefore, has lower release rates.

In acid medium $(0.1 \mathrm{HCl} ; \mathrm{pH} 1.2)$, the $D S$ release from $T 120, T 140$, $T 220$, and T240 started only after $15 \mathrm{~min}$ of test, and after $120 \mathrm{~min}$, $42 \%$ of drug was released. Unlike, the HAS tablet started the release after $5 \mathrm{~min}$ and reached $49.4 \%$ after $120 \mathrm{~min}$.

Although HAS also gelatinizes and possesses the $V$ polymorph, which is characteristic of a highly ordered crystalline structure, it is believed that the higher control of the release rates from retrograded samples is a result of the changes in the crystallinity patterns. Such modifications are caused by the retrogradation process, as the formation of resistant starch in the shape of small crystallites, for example, that can fill the void spaces of the polymeric network,

Table 3

Physical properties of the tablets.

\begin{tabular}{|c|c|c|c|c|c|}
\hline Samples & $\begin{array}{l}\text { Thickness } \\
T_{0}(\mathrm{~mm}) T_{24 h}(\mathrm{~mm})\end{array}$ & & Average weight (mg) & Hardness $(\mathrm{N})$ & Friability (\%) \\
\hline T120\% & $3.990 \pm 0.162$ & $4.081 \pm 0.154$ & $398 \pm 0.003$ & $36 \pm 0.585$ & $0.8487 \pm 0.023$ \\
\hline $\mathrm{T} 140 \%$ & $4.047 \pm 0.100$ & $4.053 \pm 0.106$ & $403 \pm 0.005$ & $38 \pm 0.445$ & $0.8833 \pm 0.194$ \\
\hline T220\% & $3.857 \pm 0.150$ & $3.940 \pm 0.154$ & $399 \pm 0.004$ & $34 \pm 0.659$ & $0.8436 \pm 0.145$ \\
\hline T240\% & $4.002 \pm 0.051$ & $4.324 \pm 0.063$ & $401 \pm 0.003$ & $37 \pm 0.503$ & $0.8124 \pm 15.95$ \\
\hline
\end{tabular}




\subsection{N Hydrochloric acid (pH 1.2)}
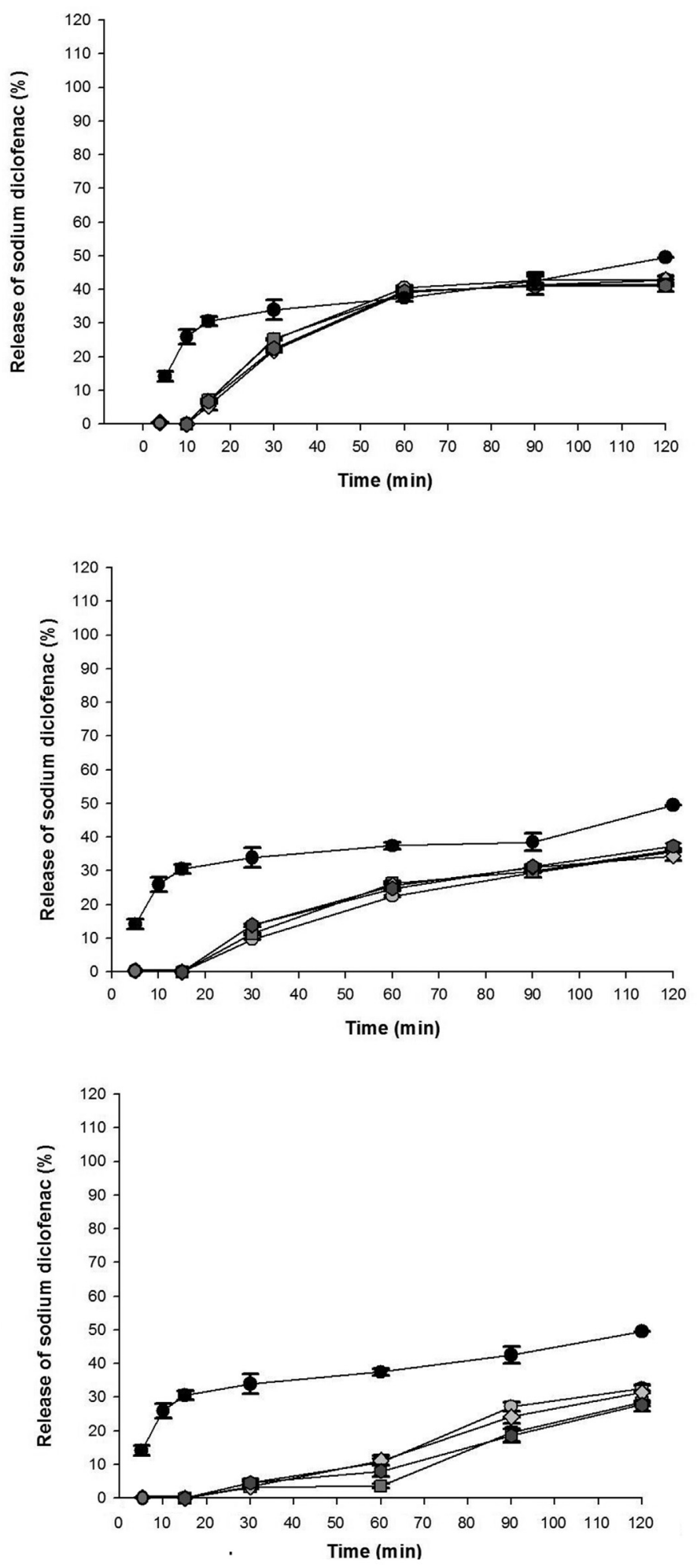

Phosphate buffer (pH 7.4)
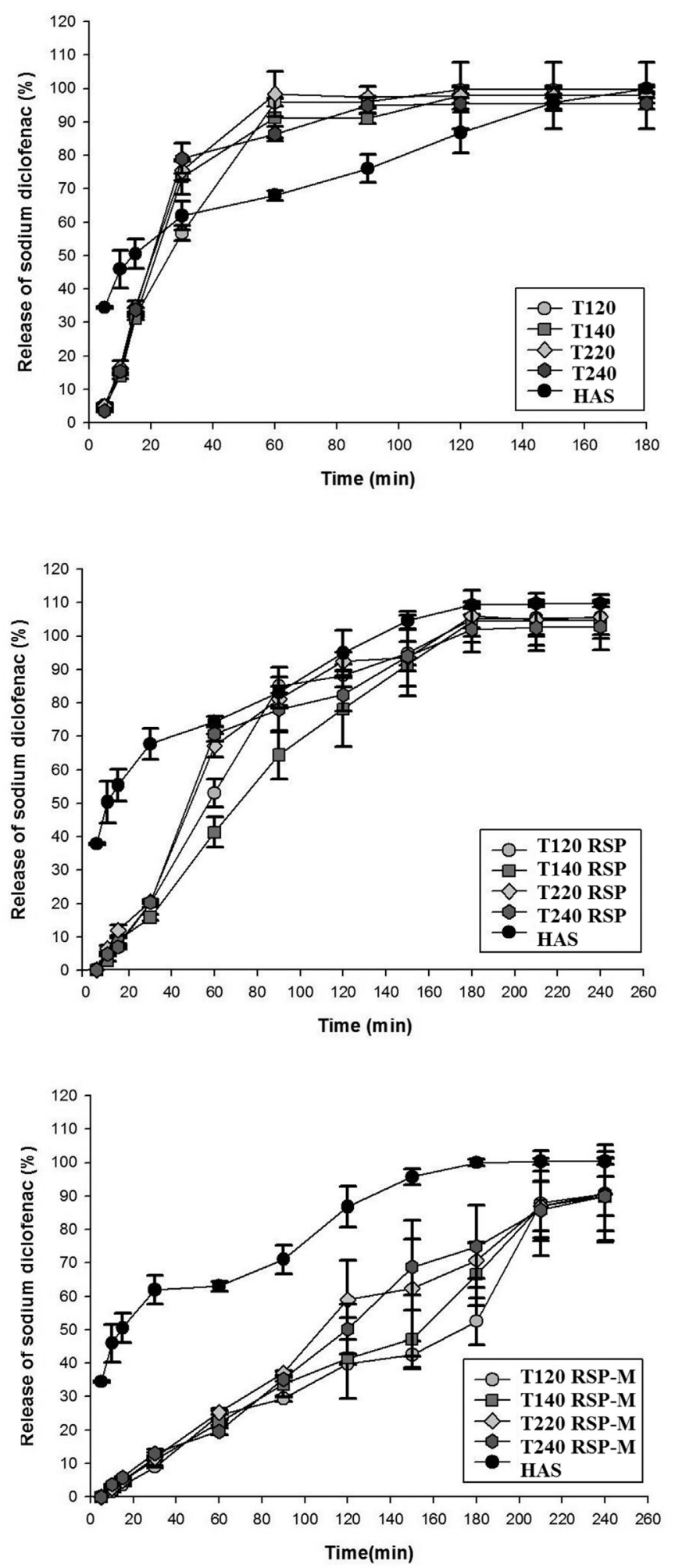

Fig. 5. In vitro drug release profiles in hydrochloric acid $(0.1 \mathrm{~N} ; \mathrm{pH} 1.2)$ and phosphate buffer (0.1 $\mathrm{M}$; $\mathrm{pH} 7.4)$.

difficulting the entrance of water and subsequent diffusion of drug molecules. Furthermore, these retrograded samples showed inferior liquid uptake in relation to the HAS, so polymeric chains should be in a more entangled state with a more viscous gel layer, hampering the diffusion of drug molecules for the dissolution medium.

However, a highest delay in the $D S$ release was observed for samples obtained with pectin addition (RSP and $R S P-M)$, as the 
Table 4

Release coefficients for DS in acid media ( $\mathrm{pH} \mathrm{1.2)} \mathrm{and} \mathrm{in} \mathrm{phosphate} \mathrm{buffer} \mathrm{(} \mathrm{pH}$ 7.4) fitted with mathematical models.

\begin{tabular}{|c|c|c|c|c|c|c|c|c|c|c|c|c|c|c|}
\hline \multirow[t]{4}{*}{ Release models } & \multicolumn{14}{|c|}{0.1 N Hydrochloric acid ( $\mathrm{pH} 1.2$ ) } \\
\hline & & \multicolumn{13}{|c|}{ SAMPLES } \\
\hline & & \multirow[t]{2}{*}{$\mathrm{T} 120$} & \multirow[t]{2}{*}{$\mathrm{T} 140$} & \multirow[t]{2}{*}{$\mathrm{T} 220$} & \multirow[t]{2}{*}{$\mathrm{T} 240$} & \multirow[t]{2}{*}{ HAS } & \multicolumn{4}{|l|}{ RSP } & \multicolumn{4}{|l|}{ RSP-M } \\
\hline & & & & & & & T120 & $\mathrm{T} 140$ & T220 & $\mathrm{T} 240$ & T120 & $\mathrm{T} 140$ & $\mathrm{~T} 220$ & $\mathrm{~T} 240$ \\
\hline \multirow[t]{3}{*}{ Weibull } & $\boldsymbol{k}$ & 43.1700 & 41.6204 & 42.5241 & 41.3635 & 11.1942 & 271.5325 & 152.1325 & 37.4176 & 51.7832 & 34.4121 & 31.5525 & 35.9721 & 32.8621 \\
\hline & $r^{2}$ & 0.9985 & 0.9999 & 0.9995 & 0.9986 & 0.9699 & 0.9998 & 0.9958 & 0.9996 & 0.9983 & 0.97514 & 0.9823 & 0.9844 & 0.9895 \\
\hline & b & 1.2191 & 1.1863 & 1.3353 & 1.3944 & 0.2354 & 0.5095 & 0.5519 & 0.8531 & 0.7215 & 1.2282 & 1.6252 & 1.4163 & 1.2914 \\
\hline \multicolumn{15}{|c|}{ Phosphate Buffer (pH 7.4) } \\
\hline \multirow[t]{3}{*}{ Korsmeyer-Peppas } & $\boldsymbol{k}$ & 0.3147 & 1.7192 & 0.2580 & 0.1583 & - & 0.1500 & 0.2347 & 0.1293 & 0.5041 & - & - & - & - \\
\hline & $r^{2}$ & 0.9990 & 0.9990 & 0.9998 & 0.9996 & - & 0.9985 & 0.9972 & 0.9899 & 0.9987 & - & - & - & - \\
\hline & $n$ & 1.7051 & 1.9202 & 1.8084 & 1.9811 & - & 1.4110 & 1.2300 & 1.5030 & 1.7470 & - & - & - & - \\
\hline \multirow[t]{3}{*}{ Weibull } & $\boldsymbol{k}$ & - & - & - & - & 204.532 & - & - & - & - & 49.8502 & 65.380 & 23.980 & 19.097 \\
\hline & $r^{2}$ & - & - & - & - & 0.9974 & - & - & - & - & 0.9937 & 0.9994 & 0.9943 & 0.9904 \\
\hline & b & - & - & - & - & 0.2770 & - & - & - & - & 1.2130 & 1.1340 & 1.2780 & 1.2470 \\
\hline
\end{tabular}

release started only after $30 \mathrm{~min}$ of test. Moreover, it was verified an important reduction of release rates ( $\sim 35 \%$ from $R S P, 30 \%$ from $R S P$ $M$ and $25 \%$ from T140RSP-M) after $120 \mathrm{~min}$. This behavior was attributed to the pectin presence, which forms insoluble aggregates in acid medium [75] and allows the building of a swollen layer that controls the release rates [76].

The increase of $\mathrm{pH}$ from 1.2 to 7.4 probably caused an expansion of the polymeric network due to the ionization of carboxylate groups, contributing to the drug diffusion and to increase of the release rates [31]. The ionization of DS in increased $\mathrm{pH}(p k a \sim 4)$ also contributes to enhance the drug release rates, favoring the dissolution process. So, the DS release from T120, T140, T220 and T240 samples reached $100 \%$ in 60 min, against $87 \%$ in 120 min from HAS tablets, fact that was attributed to the formation of a more cohesive gelled matrix [62]. Drug release of RSP and RSP-M was significantly sustained to $240 \mathrm{~min}$.

The analysis time for reaching $80 \%$ of the drug release $\left(t_{80 \%}\right)$ in $0.1 \mathrm{M}$ phosphate buffer ( $\mathrm{pH} 7.4$ ) shows that RSP-M samples allowed control for a longer time $\left(t_{80 \%}=210 \mathrm{~min}\right)$ than $R S P\left(t_{80 \%=} 150 \mathrm{~min}\right)$. This behavioral difference was assigned to conditions of retrogradation process for $R S P$, possibly leading to changes in pectin properties, and therefore, resulting in the viscosity reduction of the gel layer formed during the dissolution process.

\subsection{Analysis of in vitro drug release mechanisms}

Based on the values of adjusted $r^{2}$ (Table 4), it can be noted that in acid medium all samples fitted better with the Weibull model, wherein for samples obtained by $M 1$ and $M 2$ methods and RSP-M samples a complex mechanism of release $(b=1.186-1.625)$, involving simultaneously the relaxation of the polymer chains and erosion of the polymer during the release of the drug was observed.

However, for HAS tablets in acid and phosphate buffer, the DS release occurred by Fickian diffusion $(b=0.2354 ; b=0.2770$, respectively), while for the $R S P$ in acid medium the release was reported according to the anomalous Fickian transport $(b=0.5095$ to 0.8531 ), i.e., depending on the processes of diffusion and polymer relaxation.

In phosphate buffer ( $\mathrm{pH} 7.4$ ), M1, M2 and RSP samples fitted better to the Korsmeyer-Peppas. This change of drug release mechanism was considered consistent as these samples also showed pH-dependent swelling and release behavior. A complex mechanism classified as super case II transport ( $n=1.230-1.981)$ was observed, which implies a high rate of medium permeation through the matrix, enhancing the erosion process of system [77].

For RSP-M, the pH change from 1.2 to 7.4 did not lead to changes in the release mechanism.

\section{Conclusions}

The previously exploited methods for retrogradation of HAS were efficient, as they have provided materials with high RS contents, increased resistance to enzymatic digestion and suitable micromeritic properties. However, the structural changes promoted by different retrogradation processes did not significantly affect the release properties. Thus, similar DS release profiles exhibited by both RS from M1 and M2 evidenced that M1 represents a simpler and shorter process that should lead to the reduction of production costs. The RS blending with pectin allows the drug release for a longer time, so that different drug release features can be reached, according to different therapeutic needs, making the applicability of these materials in the development of several controlled drug delivery systems possible.

\section{Declaration of conflicts of interest}

The authors report no declarations of interest.

\section{Acknowledgements}

The authors would like to thank CAPES (Process number 23038.039439/2008-66) for providing financial support to accomplish this work. We would like to dedicate this work to the memory of our dear Professor Raul Cesar Evangelista.

\section{References}

[1] G. Kaur, D. Singh, V. Brar, Bioadhesive okra polymer based buccal patches as platform for controlled drug delivery, Int. J. Biol. Macromol. 70 (2014) 408-419.

[2] J.O. Morales, J.T. McConville, Manufacture and characterization of mucoadhesive buccal films, Eur. J. Pharm. Biopharm. 77 (2011) 187-199.

[3] A. Ceballos, M. Cirri, F. Maestrelli, G. Corti, P. Mura, Influence of formulation and process variables on in vitro release of theophylline from directlycompressed Eudragit matrix tablets, Farm. Sci. 60 (2005) 913-918.

[4] J.A. Marinich, C. Ferrero, M.R. Jiménez-Castellanos, Graft copolymers of ethy methacrylate on waxy maize starch derivatives as novel excipients for matrix tablets: drug release and fronts movement kinetics, Eur. J. Pharm. Biopharm. 80 (2012) 674-681.

[5] C. Ferrero, D. Massuelle, E. Doelker, Towards elucidation of the drug release mechanism from compressed hydrophilic matrices made of cellulose ethers. II. Evaluation of a possible swelling-controlled drug release mechanism using dimensionless analysis, J. Control. Release 141 (2010) 223-233.

[6] T. Osmałek, A. Froelich, S. Tasarek, Application of gellan gum in pharmacy and medicine, Int. J. Pharm. 466 (2014) 328-340.

[7] M. Efentakis, S. Politis, Comparative evaluation of various structures in polymer controlled drug delivery systems and the effect of their morphology and 
characteristics on drug release, Eur. Polym. J. 42 (2006) 1183-1195.

[8] C. Ferrero, M.R. Jiménez-Castellanos, In vitro release testing of matrices based on starch-methyl methacrylate copolymers: effect of tablet crushing force, dissolution medium pH and stirring rate, Int. J. Pharm. 461 (2014) 270-279.

[9] M. Levina, A.R. Rajabi-Siahboomi, The influence of excipients on drug release from hydroxypropyl methylcellulose matrices, J. Pharm. Sci. 93 (2004) $2746-2754$.

[10] C. Mura, A. Nácher, V. Merino, M. Merino-Sanjuán, M. Manconi, G. Loya, A.M. Fadda, O. Díez-Sales, Design, characterization and in vitro evaluation of 5 aminosalicylic acid loaded N-succinyl-chitosan microparticles for colon specific delivery, Colloid. Surf. B 94 (2012) 199-205.

[11] G.A. Soares, A.D. Castro, B.S.F. Cury, R.C. Evangelista, Blends of cross-linked high amylose starch/pectin loaded with diclofenac, Carbohyd. Polym. 91 (2013) 135-142.

[12] J. Peerapattana, P. Phuvarit, V. Srijesdaruk, D. Preechagoon, A. Tattawasart, Pregelatinized glutinous rice starch as a sustained release agent for tablet preparations, Carbohyd. Polym. 80 (2010) 453-459.

[13] A.B. Meneguin, B.S.F. Cury, R.C. Evangelista, Films from resistant starch-pectin dispersions intended for colonic drug delivery, Carbohyd. Polym. 99 (2014) $140-149$.

[14] M.M. Friciu, T.C. Le, P. Ispas-Szabo, M.A. Mateescu, Carboxymethyl starch and lecithin complex as matrix for targeted drug delivery: I. Monolithic Mesalamine forms for colon delivery, Eur. J. Pharm. Biopharm. 85 (2013) 521-530.

[15] E.R. Zavareze, A.R.G. Dias, Impact of heat-moisture treatment and annealing in starches: a review, Carbohyd. Polym. 83 (2011) 317-328.

[16] H.J. Chung, H.S. Lim, S.T. Lim ST, Effect of partial gelatinization and retrogradation on the enzymatic digestion of waxy rice starch, J. Cereal. Sci. 43 (2006) 353-359.

[17] D.B. Thompson, Strategies for the manufacture of resistant starch, Trends Food. Sci. Tech. 11 (2000) 245-253.

[18] S.G. Haralampu, Resistant starch - a review of the physical properties and biological impact of RS3, Carbohyd. Polym. 41 (2000) 285-292.

[19] R.C. Eerlingen, J.A. Delcour, Formation, analysis, structure and properties of type III enzyme resistant starch, J. Cereal S. C. 22 (1995) 129-138.

[20] H.N. Englyst, J.H. Cummings, Digestion of polysaccharides of potato in the small intestine of man, Am. J. Clin. Nutr. 45 (1987) 423-431.

[21] A.K. Htoon, S. Uthayakumaran, U. Piyasiri, A.M. Appelqvist, A. López-Rubio, E.P. Gilbert, R.J. Mulder, The effect of acid dextrinisation on enzyme-resistant starch content in extruded maize starch, Food Chem. 120 (2010) 140-149.

[22] J. Maior, A.V. Reis, E.C. Muniz, A.O. Cavalcanti, Reaction of pectil and glycidylmethacrilate and ulterior formation of free films by reticulation, Int. J. Pharm. 355 (2008) 184-194.

[23] B.F. Choonara, Y.E. Choonara, P.K. Kumar, D. Bijukumar, L.C. Toit, V. Pillay, A review of advanced oral drug delivery technologies facilitating the protection and absorption of protein and peptide molecules, Biotechnol. Adv. 32 (2014) 1269-1282.

[24] A. Maroni, L. Zema, M.D. Curto, A. Foppoli, A. Gazzaniga A, Oral colon delivery of insulin with the aid of functional adjuvants, Adv. Drug Deliv. Rev. 64 (2012) $540-556$.

[25] A. Maroni, M.D. Del Curto, L. Zema, A. Foppoli, A. Gazzaniga, Film coatings for oral colon delivery, Int. J. Pharm. 457 (2013) 372-394.

[26] P. Le Bail, F.G. Morin, R.H. Marchessault, Characterization of a crosslinked high amylose starch excipient, Int. J. Biol. Macromol. 26 (1999) 193-200.

[27] R. Cui, C.G. Oates, The effect of retrogradation on enzyme susceptibility of sago starch, Carbohyd. Polym. 32 (1997) 65-72.

[28] J.A.L. Silva, M.A. Rao, Pectins: structure, functionality, and uses, in: A.M. Stephen, G.O. Phillips, P.A. Williams (Eds.), Food Polysaccharides and Their Applications, CRC Press LLC, Boca Raton, 2006, pp. 353-411.

[29] B.S.F. Cury, A.B. Meneguin, V.M.O. Cardoso, F.G. Prezotti, Oral drug release systems based on pectin, in: P.L. Bush (Ed.), Pectin: Chemical Properties, Uses and Health Benefits, Nova Publishers, New York, 2014, pp. 65-81.

[30] F.M. Carbinatto, A.D. Castro, R.C. Evangelista, B.S.F. Cury, Insights into the swelling process and drug release mechanisms from cross-linked pectin/high amylose starch matrices, Asian J. Pharm. Sci. 9 (2014) 27-34.

[31] F.G. Prezotti, B.S.F. Cury, R.C. Evangelista, Mucoadhesive beads of gellan gum/ pectin intended to controlled delivery of drugs, Carbohydr. Polym. 113 (2014) 286-295.

[32] F.G. Prezotti, A.B. Meneguin, R.C. Evangelista, B.S.F. Cury, Preparation and characterization of free films of high amylose/pectin mixtures crosslinked with sodium trimetaphosphate, Drug Dev. Ind. Pharm. 38 (2012) 1-6.

[33] A.B. Meneguin, B.S.F. Cury, A.M. Santos, D.F. Franco, H.S. Barud, E.C. Silva Filho, Resistant starch/pectin free-standing films reinforced with nanocellulose intended for colonic methotrexate release, Carbohyd. Polym. 157 (2017) $1013-1023$.

[34] E.Y. Park, B.K. Baik, S.T. Lim, Influences of temperature-cycled storage on retrogradation and in vitro digestibility of waxy maize starch gel, J. Cereal Sci. 50 (2009) 43-48.

[35] H.N. Englyst, H.S. Wiggins, J.H. Cummings, Determination of the non-starch polysaccharides in plant foods by gas liquid chromatography of constituent sugars asalditol acetates, Analyst 107 (1982) 307-318.

[36] P. Bernfeld, Amylases, alpha and beta, in: Methods in Enzymology I, Academic Press, New York, 1955.

[37] J. Zhang, Z.U. Wang, Optimization of reaction conditions for resistant Canna edulis Ker starch phosphorylation and its structural characterization, Ind. Crop. Prod. 30 (2009) 105-113.
[38] M. Casas, C. Ferrero, M.V. Paz, M.R. Jiménez-Castellanos, Synthesis and characterization of new copolymers of ethyl methacrylate grafted on tapioca starch as novel excipients for direct compression matrix tablets, Eur. Polym. J. 45 (2009) 1765-1776.

[39] E.L. Parrot, Pharmaceutical Technology: Fundamental Pharmaceutics, Burgess Publishing Company, Minneapolis, 1970.

[40] D. Train, Some aspects of the property of angle of repose of powders, J. Pharm. Pharmacol. 10 (1958), 127T-35T.

[41] S. Brunauer, P.H. Emmett, E. Teller, Adsorption of gases in multimolecular layers, J. Am. Chem. Soc. 60 (1938) 309-319.

[42] B.S.F. Cury, A.D. Castro, S.I. Klein, R.C. Evangelista, Modeling a system of phosphated cross-linked high amylose for controlled drug release. Part 2: physical parameters, cross-linking degrees and drug delivery relationships, Int. J. Pharm. 371 (2009) 8-15.

[43] R. Voigt, Pharmazeutische technologie: für Studium und Beruf, ninth ed., Deutscher Apotheker, Stuttgart, 2000.

[44] United States Pharmacopeia \& National Formulary, Pharmacopeial Convention United States, thirty-first ed., 2008.

[45] A. Flores-Morales, M. Jiménez-Estrada, R. Mora-Escobedo, Determination of the structural changes by FT-IR, Raman, and CP/MAS 13C NMR spectroscopy on retrograded starch of maize tortillas, Carbohyd. Polym. 87 (2012) 61-68.

[46] A.C. Freire, C.C. Fertig, F. Podczeck, F. Veiga, J. Sousa, Starch-based coatings for colon-specific drug delivery. Part I: the influence of heat treatment on the physico-chemical properties of high amylose maize starches, Eur. J. Pharm. Biopharm. 72 (2009) 574-586.

[47] P.J. Wilson, A.W. Basit, Exploiting gastrointestinal bacteria to target drugs to the colon: an in vitro study using amylose coated tablets, Int. J. Pharm. 300 (2005) 89-94.

[48] J. Juansang, C. Puttanlek, V. Rungsardthong, S. Puncha-Arnon, D. Uttapap, Effect of gelatinization on slowly digestible starch and resistant starch of heatmoisture treated and chemically modified canna starches, Food Chem. 131 (2012) 500-507.

[49] J. Silverio, H. Fredriksson, R. Andersson, A.C. Eliasson, P. Åman, The effect of temperature cycling on the amylopectin retrogradation of starches with different amylopectin unit-chain length distribution, Carbohyd. Polym. 42 (2000) 175-184.

[50] D. Sievert, Z. Czuchajowska, Y. Pomeranz, Enzyme-resistant starch. III. X-ray diffraction of autoclaved amylomaize VII starch and enzyme-resistant starch residues, Cereal Chem. 68 (1991) 86-91.

[51] I. Bravo-Osuna, C. Ferrero, M.R. Jimenéz-Castellanos, Influence of moisture content on the mechanical properties of methyl methacrylate-starch copolymers, Eur. J. Pharm. Biopharm. 66 (2007) 63-72.

[52] A.O. Ferreira, Guia Prático da Farmácia Magistral, second ed., Pharmabooks, Juiz de Fora, 2002.

[53] R.C. Rowe, P.J. Sheskey, M.E. Quinn, Handbook of Pharmaceutical Excipients, sixth ed., Pharmaceutical Press, London, 2009.

[54] V. Kumar, M.L. Reus-Medina, D. Yang, Preparation, characterization, and tabletting properties of a new cellulose-based pharmaceutical aid, Int. J. Pharm. 235 (2002) 129-140.

[55] S. Zabar, E. Shimoni, H. Bianco-Peled, Development of nanostructure in resistant starch type III during thermal treatments and cycling, Macromol. Biosci. 8 (2008) 163-170.

[56] F.M. Carbinatto, A.D. Castro, B.S.F. Cury, A. Magalhães, R.C. Evangelista, Physical properties of pectin-high amylose starch mixtures cross-linked with sodium trimetaphosphate, Int. J. Pharm. 423 (2012) 281-288.

[57] K. Shamai, H. Bianco-Peled, E. Shimoni, Polymorphism of resistant starch type III, Carbohyd. Polym. 54 (2003) 363-369.

[58] T.P. Coultate, Food: the Chemistry of its Components, fifth ed., RSC Publishing, Cambridge, 2002.

[59] L. Peng, L. Zhongdong, J.F. Kennedy, The study of starch nano-unit chains in the gelatinization process, Carbohyd. Polym. 68 (2007) 360-366.

[60] P. Aggarwal, D.A. Dollimore, Thermal analysis investigation of partially hydrolyzed starch, Thermochim. Acta 319 (1998) 17-25.

[61] K. Kawai, K. Fukami, K. Yamamoto, Effect of temperature on gelatinization and retrogradation in high hydrostatic pressure treatment of potato starch-water mixtures, Carbohyd. Polym. 87 (2012) 314-321.

[62] T.M. Crowder, A.J. Hickey, M.D. Louey, N. Orr, A Guide to Pharmaceutical Particulate Science, CRC Press LLC, Boca Raton, 2003.

[63] J.L.A. Albero, A Operação de Prensagem: considerações Técnicas e sua Aplicação Industrial Parte I: O Preenchimento das Cavidades do Molde, Ceram. Ind. 5 (2000) 23-28.

[64] Włodarczyk M. Stasiak, J. Jamroz, Specific surface area and porosity of starch extrudates determined from nitrogen adsorption data, J. Food Eng. 93 (2009) $379-385$.

[65] G.A. Soares, F.M. Carbinatto, B.S.F. Cury, R.C. Evangelista, Effect of drying technique on some physical properties of cross-linked high amylose/pectin mixtures, Drug Dev. Ind. Pharm. 39 (2013) 284-289.

[66] J. Rouquerol, D. Avnir, C.W. Fairbridge, D.H. Everett, J.H. Haynes, N. Pernicone, J.D.F. Ramsay, K.S.W. Sing, K.K. Unger, Recommendations for the characterization of porous solids, Pure Appl. Chem. 66 (1994) 1739-1758.

[67] M. Efentakis, M. Viachou, N.H. Choulis, Effects of excipients on swelling and drug release from compressed matrices, Drug Dev. Ind. Pharm. 23 (1997) $107-112$.

[68] J. Mulhbacher, P. Ispas-Szabo, M.A. Mateescu, Cross-linked high amylose starch derivatives for drug release: II. Swelling properties and mechanistic 
study, Int. J. Pharm. 278 (2004) 231-238.

[69] J.P. Souto-Maior, A.V. Reis, L.N. Pedreiro, O.A. Cavalcanti, Phosphated crosslinked pectin as a potential excipient for specific drug delivery: preparation and physicochemical characterization, Polym. Int. 59 (2010) 127-135.

[70] A.K. Bajpai, S.K. Shukla, S. Bhanu, S. Kankane, Responsive polymers in controlled drug delivery, Progres. Polym. Sci. 33 (2008) 1088-1118.

[71] H.W. Leach, L.D. Mccowen, T.J. Schoch, Structure of the starch granule. I. Swelling and solubility patterns of various patterns of various starches, Cereal Chem. 36 (1959) 534-544.

[72] P. Sriburi, S.E. Hill, Extrusion of cassava starch with either variations in ascorbic acid concentration or pH, Int. J. Food Sci. Tech. 35 (2000) 141-154.

[73] C.M. Lopes, J.M.M. Lobo, P. Costa, Formas Farmacêuticas de liberação modificada: polímeros hidrifílicos, Rev. Bras. Cienc. Farm 41 (2005) 143-154.

74] M. Grassi, G. Grassi, R. Lapasin, I. Colombo, Drug Release from Matrix Systems, CRC press, Boca Raton, 2006.

[75] L.S. Liu, M.L. Fishman, J. Kost, K.B. Hicks, Pectin based systems for colonspecific drug delivery via oral route, Biomaterial 24 (2003) 3333-3343.

[76] F. Bigucci, B. Luppi, T. Cerchiara, M. Sorrenti, G. Bettinetti, L. Rodrigues, V. Zecchi, Chitosan/pectin polyelectrolyte complexes: selection of suitable preparative conditions for colon-specific delivery of vancomycin, Eur. J. Pharm. Sci. 35 (2008) 435-441.

[77] D.L. Munday, P.J. Cox, Compressed xanthan and karaya gum matrices: hydration, erosion and drug release mechanisms, Int. J. Pharm. 203 (2000) 179-192. 